\title{
əToward All-Sky Assimilation of Microwave Temperature Sounding Channels in Environment Canada's Global Deterministic Weather Prediction System
}

\author{
MAZIAR BANi SHAHABADI ${ }^{\mathrm{a}}$ AND MARK BUEHNER ${ }^{\mathrm{a}}$ \\ ${ }^{a}$ Meteorological Research Division, Environment and Climate Change Canada, Dorval, Quebec
}

(Manuscript received 5 March 2021, in final form 31 August 2021)

\begin{abstract}
The all-sky assimilation of radiances from microwave instruments is developed in the 4D-EnVar analysis system at Environment and Climate Change Canada (ECCC). Assimilation of cloud-affected radiances from Advanced Microwave Sounding Unit-A (AMSU-A) temperature sounding channels 4 and 5 for non-precipitating scenes over the ocean surface is the focus of this study. Cloud-affected radiances are discarded in the ECCC operational data assimilation system due to the limitations of forecast model physics, radiative transfer models, and the strong nonlinearity of the observation operator. In addition to using symmetric estimate of innovation standard deviation for quality control, a statedependent observation error inflation is employed at the analysis stage. The background-state clouds are scaled by a factor of 0.5 to compensate for a systematic overestimation by the forecast model before being used in the observation operator. The changes in the fit of the background state to observations show mixed results. The number of AMSU-A channels 4 and 5 assimilated observations in the all-sky experiment is $5 \%-12 \%$ higher than in the operational system. The all-sky approach improves temperature analysis when verified against ECMWF operational analysis in the areas where the extra cloudaffected observations were assimilated. Statistically significant reductions in error standard deviation by $1 \%-4 \%$ for the analysis and forecasts of temperature, specific humidity, and horizontal wind speed up to maximum 4 days were achieved in the all-sky experiment in the lower troposphere. These improvements result mainly from the use of cloud information for computing the observation-minus-background departures. The operational implementation of all-sky assimilation is planned for the fall of 2021.
\end{abstract}

KEYWORDS: Satellite observations; Numerical weather prediction/forecasting; Data assimilation

\section{Introduction}

Satellite radiances are the dominant observation type in terms of the number of assimilated observations for numerical weather prediction (NWP) (Buehner et al. 2018). Improvements of the use of radiance observations in operational data assimilation systems benefit NWP, especially for areas of the atmosphere where satellite radiances are the only available observations. Data assimilation systems have primarily used cloud-free radiance observations (Geer et al. 2018) due to the limitations of forecast model physics, radiative transfer models, and the strong nonlinearity of the observation operator for cloud-affected radiance observations.

In recent years, substantial effort has been dedicated to making use of cloud- and precipitation-affected radiance observations in NWP centers across the world. The European Centre for Medium-Range Weather Forecasts (ECMWF) was the first center to achieve the operational implementation of the all-sky microwave radiance assimilation for observations from the Special Sensor Microwave Imager (SSM/I) and Advanced Microwave Scanning Radiometer for the Earth Observing System (AMSR-E) in 2009 (Bauer et al. 2010). Since then, continuous development at ECMWF has supported the all-sky

\footnotetext{
D Denotes content that is immediately available upon publication as open access.
}

Corresponding author: Maziar Bani Shahabadi, maziar. banishahabadi@ec.gc.ca assimilation of more microwave observations from three imager and nine sounding instruments in their 4D-Var system (Geer et al. 2018). In these implementations, the symmetric model for observation minus background departures (referred to as the innovations) standard deviation (Geer and Bauer 2011) was used to increase observation error standard deviation (stddev) as a function of hydrometeor amount. The assimilation of microwave radiances sensitive to humidity, cloud, and precipitation has improved the ECWMF's global forecast skill of temperature, geopotential height, wind vector, and precipitation up to day 6 (Geer et al. 2017). The all-sky assimilation of Advanced Microwave Sounding Unit-A (AMSUA) temperature sounding channels at the Met Office showed a $1 \%$ reduction in root-mean-square error (RMSE) of geopotential height forecasts at $500-\mathrm{hPa}$ up to day 2 , a $1 \%$ reduction in RMSE of 10-m wind and 2-m temperature forecasts up to day 6, and significant improvements in the fit of the background state to the observations for low-peaking humidity and temperature channels (Migliorini and Candy 2019).

Non-precipitating cloud-affected observations of AMSU-A channels $1-5$ and 15 have been assimilated over the oceans in the National Centers for Environmental Prediction (NCEP) operational Global Forecast System (GFS) since 2016 (Zhu et al. 2016) with results indicating neutral impact on the anomaly correlation of geopotential height at $500 \mathrm{hPa}$ and RMSE of temperature forecasts at $850 \mathrm{hPa}$. The all-sky assimilation of the non-precipitating cloud-affected radiances at NCEP was later extended to the Advanced Technology Microwave Sounder (ATMS) instrument (Zhu et al. 2019, Tong et al. 2020). Furthermore, Tong et al. (2020) studied the impact of replacing 
the original cloud water control variable by five hydrometeors, namely, cloud liquid water, cloud ice, rain, snow, and graupel, as the new control variables used for the all-sky assimilation of radiances at NCEP and they report the impacts in the following text derived from there with minor modifications: "The improvements were found in $500-\mathrm{hPa}$ geopotential height forecast in both the Northern and Southern Hemispheres and in temperature forecast at $850 \mathrm{hPa}$ in the Southern Hemisphere and the tropics."

Kazumori and Kadowaki (2017) describe the implementation of the all-sky assimilation of microwave radiances in the Japan Meteorological Agency (JMA) global data assimilation system. The following text is derived from there with minor modifications "The all-sky assimilation improved lower -tropospheric temperature, humidity, and wind in the analysis and forecast. The low-tropospheric improvements were attributed to the allsky assimilation of microwave imagers, whereas the all-sky assimilation of humidity sounders resulted in mid- and uppertropospheric humidity and wind improvements."

At Environment and Climate Change Canada (ECCC), only the clear-sky radiances are assimilated within the current operational 4D-EnVar system. This study demonstrates the initial steps toward the all-sky assimilation of microwave radiances at ECCC in the global deterministic weather prediction system (Buehner et al. 2015; McTaggart-Cowan et al. 2019). Rather than starting from the all-sky assimilation of microwave imagers and extending the methodology to the microwave sounders, as done at ECMWF, we tried to increase the yield of microwave sounding instruments by assimilating the cloud-affected observations and benefit from the large forecast impact of AMSU-A observations shown by the Forecast Sensitivity to Observation Impact (FSOI) study in Migliorini and Candy (2019). We focus on the assimilation of cloud-affected AMSU-A channels 4 and 5 observations which are sensitive to atmospheric temperature variations in the lower troposphere, over the ocean surface for nonprecipitating scenes. This study only partially addresses the "all-sky" approach applied to AMSU-A, since the precipitating observations are still not used. However, for simplicity the term "all-sky" will still be used throughout the text. The precipitating cloudy observations are excluded to avoid the need to simulate scattering of radiation by hydrometeors. Geer et al. (2012) reported degradation of temperature forecasts at $850 \mathrm{hPa}$ in the tropics with the all-sky assimilation of AMSU-A channels 4 and 5 at ECMWF. At ECCC, these efforts have yielded positive results, which will be presented in the following sections and possible explanations for these differences are discussed. Consequently, the all-sky assimilation of AMSU-A channels 4 and 5 is included in a set of upgrades to the operational systems, planned for the fall of 2021.

This paper is organized as follows. Section 2 describes the details of the current ECCC global radiance assimilation components, including quality control, bias correction, and the 4D-EnVar system. The changes made to each component to support the all-sky assimilation functionality are presented in section 3. The improvements from the all-sky radiance assimilation are highlighted in terms of the fit of the background state to the observation, and the analysis and forecast skill improvements in section 4. Section 5 summarizes the findings and concludes this study.

\section{The original clear-sky assimilation system}

The observation operator used in the ECCC operational data assimilation system for radiance observations is version 12.1 of the RTTOV radiative transfer model (Saunders et al. 2018). The model state variables (not including clouds) are interpolated from the 3D gridded background state to the observation times and locations to construct the RTTOV input profile for the simulation and assimilation of radiance observations. The slant-path radiative transfer for simulation and assimilation of radiances (Shahabadi et al. 2018, 2020) is included for the operational implementation planned for the fall of 2021 and is not part of the current operational system. Therefore, this feature is not activated in the tests performed for this study.

\section{a. Quality control}

The observations go through quality control and thinning prior to being considered for assimilation. The clear-sky quality control screens out the observations affected by clouds and precipitation in the operational system. Model cloud information is not used in the observation operator for simulating radiance observations. For AMSU-A observations over the ocean surface, the retrieval formula of Grody et al. (2001) is used to compute integrated Cloud Liquid Water $\left(\mathrm{CLW}, \mathrm{kg} \mathrm{m}^{-2}\right)$ :

$$
\mathrm{CLW}=\cos \theta\left[c_{0}+c_{1} \ln \left(285-\mathrm{BT}_{1}\right)+c_{2} \ln \left(285-\mathrm{BT}_{2}\right)\right],
$$

where $c_{0}=8.240-(2.622-1.846 \cos \theta) \cos \theta\left(\mathrm{kg} \mathrm{m}^{-2}\right) ; c_{1}=$ $0.754\left(\mathrm{~kg} \mathrm{~m}^{-2}\right), c_{2}=-2.265\left(\mathrm{~kg} \mathrm{~m}^{-2}\right) ; \theta$ is the zenith angle; and $\mathrm{BT}_{1}$ and $\mathrm{BT}_{2}$ are AMSU-A channels 1 and 2 brightness temperatures, respectively. In the current operational system, AMSU-A channels 1-3 and 15 are not assimilated, while channels 4 and 5 are only assimilated over the ocean surface when CLW $<0.3$.

Moreover, the scattering index (Grody et al. 1999) is used to screen out AMSU-A observations affected by thick clouds and precipitation:

$$
S=-113.2+\left(2.41-0.0049 \mathrm{BT}_{1}\right) \mathrm{BT}_{1}+0.454 \mathrm{BT}_{2}-\mathrm{BT}_{15},
$$

where $\mathrm{BT}_{15}$ is $\mathrm{AMSU}-\mathrm{A}$ channel 15 brightness temperature. AMSU-A channels 4-6 are rejected if $S>9$.

The so-called rogue check is the final test for AMSU-A quality control. If the difference between the observed brightness temperature and the corresponding value simulated using the background state $(\mathrm{OMB})$ is larger than a constant factor $(F)$ times the constant precomputed innovation stddev $(\sigma)$, the observation is rejected from assimilation. Even though AMSU-A observations of channels 1-3 are not assimilated, the quality control procedure is still applied to them. Rejection of any observations of channels 1-3 will induce removal of the corresponding observations of channels 4 and 5 from assimilation. As 
TABLE 1. Constant factor $(F)$ and constant innovation stddev $(\sigma)$ used for AMSU-A MetOp-1 clear-sky rogue check.

\begin{tabular}{cll}
\hline \hline Channel & $F$ & \multicolumn{1}{c}{$\sigma$} \\
\hline 1 & 2 & 3.4 \\
2 & 2 & 2.7 \\
3 & 2 & 1.9 \\
4 & 3 & 0.31 \\
5 & 4 & 0.185 \\
\hline
\end{tabular}

an example, Table 1 indicates the values of $F$ and $\sigma$ used for the AMSU-A MetOp-1 clear-sky rogue check.

Spatial thinning is applied to the observations not flagged for rejection to reduce the effect of spatial error correlation. After spatial thinning, the minimum distance between all radiance observations is about $150 \mathrm{~km}$ in the current ECCC operational global deterministic prediction system.

\section{b. Bias correction}

At ECCC, satellite radiances are bias corrected using dynamically computed bias model coefficients. As described in Buehner et al. (2015), a 3DVar analysis in which only the nonradiance observations are assimilated, is used as an unbiased reference state. Linear regression is used to estimate the bias model coefficients by fitting the quality controlled and thinned radiance observations to the past seven days of these $3 \mathrm{DV}$ ar analyses. The bias model predictors for satellite radiance observations are 1000-300-, 200-50-, and 50-5-hPa geopotential height thicknesses, and a scan-dependent bias. The biases are calculated and applied for each instrument and channel of a given satellite separately.

\section{c. 4D-EnVar system}

In the 4D-EnVar assimilation system (Buehner et al. 2015) at ECCC, the background error covariances include flow-dependent and climatological contributions. The flowdependent component is estimated from ensembles of shortterm forecasts which are produced by the 256-member operational ensemble Kalman filter (Houtekamer et al. 2019). The climatological estimate is from a static term produced using the so-called National Meteorological Center method (NMC; Parrish and Derber 1992) and estimates the forecast errors using the differences between 24- and 48-h forecasts valid at the same time.

The description of the currently assimilated observations in ECCC's 4D-EnVar system parallels that of Shahabadi et al. (2019) as follows "The length of the assimilation window is $6 \mathrm{~h}$, and it is discretized in 15-min time slots for calculating the innovations of the assimilated observations. About 13 million observations per day are currently assimilated in the operational global system and include those from radiosondes, aircrafts, land stations, ships and buoys, scatterometers, atmospheric motion vectors, satellite-based radio occultation, ground-based GPS instruments and microwave and infrared satellite sounders and imagers. The analyzed variables are the horizontal winds, temperature, humidity, surface pressure, and surface skin temperature."
There is no outer-loop in ECCC's 4D-EnVar assimilation system. The incremental approach is used to compute the analysis increments and the cost function gradient on a lowerresolution horizontal grid (39-km grid spacing) than the atmospheric model grid used to compute the innovations $(15-\mathrm{km}$ grid spacing).

To obtain the observation error stddev used at the analysis step, the constant innovation stddev used at the quality control stage ( $\sigma$ in Table 1 for AMSU-A channels $1-5$ observations) are inflated by a multiplicative factor (IF) that accounts for the neglected spatial observation error correlations. The inflation factors for AMSU-A channels 4 and 5 are 1.6 and 1.4, respectively.

\section{Modifications for the all-sky assimilation}

Liquid cloud profile (LCP), in addition to the non-cloud model state variables, are used in the observation operator in the all-sky system for simulation and assimilation of AMSU-A temperature sounding channels 4 and 5 over the ocean surface for non-precipitating scenes. Compared to the operational system, no other changes are made for the simulation and assimilation of other AMSU-A channels.

LCP is the total specific cloud water content computed by the forecast model and passed to its own radiative transfer scheme. The following description of forecast model clouds is derived from McTaggart-Cowan et al. (2019), with minor modifications, "Model clouds are created by the boundary layer scheme, the moist convection schemes, and the gridscale condensation scheme. At each model time step, the model physics parametrization generates the LCP field by combining cloud estimates from all potential sources, including the prognostic 'explicit' cloud, generated by the gridscale condensation scheme, and the 'implicit' cloud arising from all other sources (deep convection, shallow convection, and boundary layer clouds)."

Due to the current lack of an outer-loop in the ECCC 4DEnVar assimilation system, we solely rely on the quality of the background-state clouds to realistically simulate AMSU-A observations when computing the innovations in the areas where model cloud is present.

The innovation stddev used during quality control, bias correction, and the 4D-EnVar system are modified to support the all-sky capabilities. The changes are described in the following subsections.

\section{a. New innovation standard deviation for quality control and observation error definition}

The use of a constant innovation stddev ( $\sigma$ in Table 1$)$ is not suitable for use in the observation quality control of the all-sky approach as the accuracy of simulated radiances is closely related to the cloud amount and the accuracy of the background state. Over the ocean surface, CLW retrievals from both observed radiances $\left(\mathrm{CLW}_{\text {obs }}\right)$ and radiances simulated using the background state $\left(\mathrm{CLW}_{\mathrm{FG}}\right)$ are computed using Eq. (1) and averaged to yield the symmetric cloud amount $(\overline{\mathrm{CLW}})$. It is essential that the variables used to represent the observation and model cloudiness are consistent and comparable. 
TABLE 2. Piecewise linear fit parameters to define the AMSU-A channels 1-5 model for the innovation stddev in the all-sky assimilation.

\begin{tabular}{ccccc}
\hline \hline Channel & $C_{\text {clr }}\left(\mathrm{kg} \mathrm{m}^{-2}\right)$ & $C_{\text {cld }}\left(\mathrm{kg} \mathrm{m}^{-2}\right)$ & $\sigma^{\text {clr }}(\mathrm{K})$ & $\sigma^{\text {cld }}(\mathrm{K})$ \\
\hline 1 & 0.013 & 0.363 & 3.0 & 12.7 \\
2 & 0.013 & 0.363 & 2.5 & 21.0 \\
3 & 0.013 & 0.337 & 1.7 & 12.0 \\
4 & 0.013 & 0.337 & 0.3 & 2.0 \\
5 & 0.038 & 0.488 & 0.2 & 0.37 \\
\hline
\end{tabular}

This means we must work in radiance space, and use CLW retrievals to get comparable estimates of observation and model cloud amounts, as suggested by Geer and Bauer (2011). For AMSU-A channels 4 and 5 over the ocean surface, the new innovation stddev values are obtained based on the piecewise linear fit to the stddev of OMB binned by $\overline{C L W}$, as proposed by Geer and Bauer (2011) and Geer et al. (2012). This piecewise linear function describing the all-sky innovation stddev as a function of $\overline{C L W}$ is defined as

$$
\sigma^{\mathrm{all}}=\left\{\begin{array}{c}
\sigma^{\mathrm{clr}}\left(\overline{\mathrm{CLW}} \leq C_{\mathrm{clr}}\right) \\
\sigma^{\mathrm{clr}}+\lambda\left(\overline{\mathrm{CLW}}-C_{\mathrm{clr}}\right)\left(C_{\mathrm{clr}}<\overline{\mathrm{CLW}}<C_{\mathrm{cld}}\right), \\
\sigma^{\mathrm{cld}}\left(\overline{\mathrm{CLW}} \geq C_{\mathrm{cld}}\right)
\end{array}\right.
$$

where

$$
\lambda=\frac{\sigma^{\mathrm{cld}}-\sigma^{\mathrm{clr}}}{C_{\mathrm{cld}}-C_{\mathrm{clr}}}
$$

$C_{\text {clr }}$ and $C_{\text {cld }}$ are the clear and cloudy threshold values for the linear fit, respectively; and $\sigma^{\text {clr }}$ and $\sigma^{\text {cld }}$ are the clear and cloudy innovation stddev, respectively. The channel-dependent $C_{\mathrm{clr}}$, $C_{\text {cld }}, \sigma^{\text {clr }}$, and $\sigma^{\text {cld }}$ parameters of the innovation stddev model are summarized in Table 2 for AMSU-A channels 1-5. Figure 1 shows the variation of stddev of OMB (blue) and the piecewise linear fit (red) as function of $\overline{\mathrm{CLW}}$ for AMSU-A channels 4 and 5 for the period from 15 June to 11 July 2019. The data count in each bin is shown in green.

To perform the rogue check quality control of AMSU-A channels 4 and 5 observations, the same F factor (Table 1) as used in the clear-sky system is also used in the all-sky system, but applied to the cloud-dependent all-sky innovation stddev $\left[\sigma^{\text {all }}\right.$ in Eq. (3)]. Similarly, the observation error stddev used for the all-sky assimilation is computed with the same error inflation factor (IF) as used for the clear-sky assimilation, but applied to the cloud-dependent all-sky innovation stddev $\left(\sigma^{\text {all }}\right)$.

The ability of the new model for the innovation stddev to describe the OMB statistics is now examined. The histograms of OMB for all AMSU-A channels 4 and 5 radiances over the ocean surface for the period from 1 to 5 July 2019 are shown in Fig. 2. Similar to Geer et al. (2012) and Tong et al. (2020), if the OMB is normalized by the stddev of the complete data sample (blue) the distribution is non-Gaussian. However, normalization by the symmetric model for the innovation stddev brings the distribution closer to Gaussian by assigning larger error to cloudy scenes and smaller error to clear scenes (red curve) when OMB values are not too far away from zero. At large negative $\mathrm{OMB}$ values, where there is discrepancy between the Gaussian and normalization by the symmetric model for the innovation stddev distributions (green and red curves in Fig. 2), the observations are rejected at the quality control stage.

Finally, for this implementation the scan-dependent change in the model for the innovation stddev and its possible variation with latitudinal band (Geer et al. 2012) are not considered.

\section{b. Model cloud scaling}

Comparing the AMSU-A channels 4 and 5 OMB values, produced with and without using the background cloud in the observation operator, showed the OMB statistics change considerably due to the existence of model cloud. Comparison of the background and observation components of $\overline{\mathrm{CLW}}\left(\mathrm{CLW}_{\mathrm{FG}}\right.$ and $\mathrm{CLW}_{\text {obs }}$ ) showed the background-state clouds are largely overestimated $\left(\mathrm{CLW}_{\mathrm{FG}}>\mathrm{CLW}_{\mathrm{obs}}\right)$. As explained in Geer et al. (2012), the existence of cloud affects the AMSU-A channels 4 and 5 simulated brightness temperatures by two mechanisms: 1 ) cloud increases the simulated brightness temperature as it is a warm emitter over the cold ocean surface (positive feedback);2) cloud reduces the simulated brightness temperature by moving the weighting function upward where it is colder and through scattering (negative feedback). The positive feedback is dominant for AMSU-A channels 4 and 5, which their weighting functions have low-peaking altitudes and when the scattering effect is small (for non-precipitating clouds). Increasing cloud amount increases the simulated brightness temperatures and consequently decreases the OMB values.

There are overestimates of latent heat flux, boundary layer humidity, and precipitation over the ocean surface in the ECCC global forecast model (P. Vaillancourt 2020, personal communication ). To diminish the negative impact of the model cloud overestimation on the OMB statistics, the background clouds are scaled globally by a multiplicative factor, which is applied to the vertical LCP profile, before using the cloud profile in the observation operator. Applying the global multiplicative factor to model clouds is a simple solution to reduce the overall model cloud overestimation, though the OMB may still be large due to errors in the horizontal location of clouds.

The proper cloud scale factor maintains the linear relation between stddev of OMB versus $\overline{\mathrm{CLW}}$ and would suppress large negative mean of $\mathrm{OMB}$ values happening in cloudy bins $\left(\overline{\mathrm{CLW}}>0.05 \mathrm{~kg} \mathrm{~m}^{-2}\right)$. With this approach, the model cloud biases are not interpreted as observation bias and the all-sky bias correction system (section $3 \mathrm{~d}$ ) is able to remove the mean bias. We conducted multiple sensitivity experiments by running assimilation cycles with different cloud scaling factors and the factor of 0.5 yielded the best forecast results for low-tropospheric mean temperature and humidity biases. Hence, for AMSU-A channels 4 and 5 radiances over the ocean surface, the cloud scaling factor of 0.5 is used for the simulation of observations for the purposes of quality control and bias correction, and assimilation of observations in the 


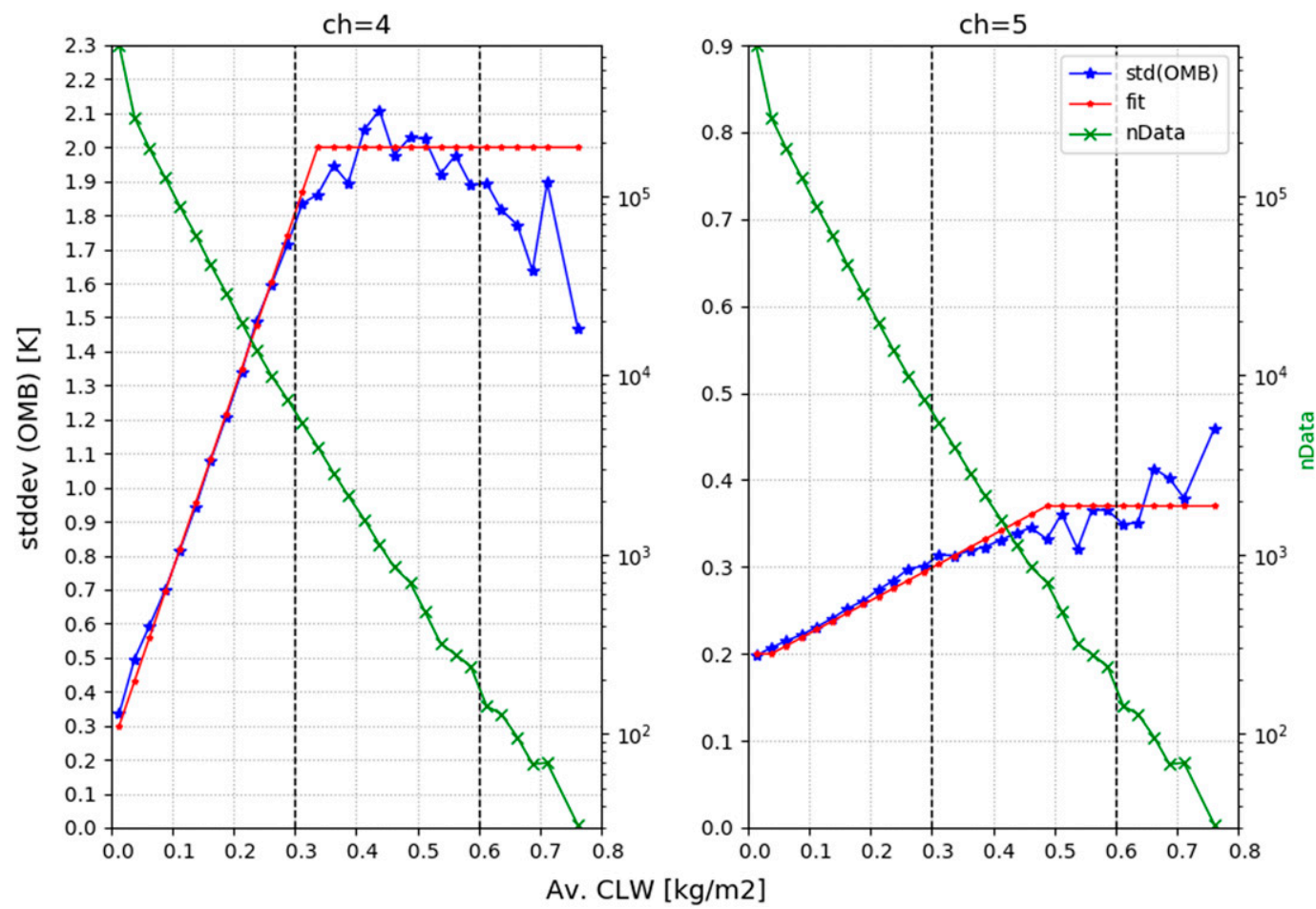

FIG. 1. The OMB stddev (K, blue) for the period from $15 \mathrm{Jun}$ to $1 \mathrm{Jul} 2019$ as function of $\overline{\mathrm{CLW}}\left(\mathrm{kg} \mathrm{m}^{-2}\right)$ for AMSU-A channels (left) 4 and (right) 5. The piecewise linear fit (red) and the data count (green) are also shown. Only the $\overline{C L W}$ bins with sample size greater than 30 are shown. The $\overline{C L W}$ bin width $0.025 \mathrm{~kg} \mathrm{~m}^{-2}$ is used to generate this plot.

4D-EnVar system. It is important to mention the cloud scaling is not used in the innovation stddev model, even though this introduces inconsistency with the data assimilation system. Refinement to the model for innovation stddev is among the items that will be examined in our future all-sky developments.

\section{c. Additional changes to quality control}

In the current all-sky implementation, AMSU-A channels 4 and 5 are assimilated only if $\overline{\mathrm{CLW}}<0.6 \mathrm{~kg} \mathrm{~m}^{-2}$. Observations with larger $\overline{\mathrm{CLW}}$ are generally associated with large OMB values and often exceed the threshold of the rogue check test in the quality control. However, this criteria is used to ensure these observations are not assimilated since the model for the innovation stddev is based on inadequate sampling of large $\overline{\mathrm{CLW}}$ bins. The overestimation of model cloud at ECCC implies that the model is most probably cloudier than the observation at large $\overline{\mathrm{CLW}}$ bins and rejecting these observations will protect the analysis. The clear-sky and all-sky $\overline{\mathrm{CLW}}$ thresholds for assimilating AMSU-A channels 4 and 5 observations are marked as vertical dashed lines on Fig. 1.

Finally, a new quality control test based on cloud effect (Geer and Bauer, 2011; Geer et al. 2012; Zhu et al. 2016) of channel 5 AMSU-A is introduced to screen out observations affected by extreme scattering, mainly from frozen hydrometeors, in deep convective regions. The following description of the approach for measuring the cloud effect parallels that of
Zhu et al. (2016), which is "the difference between brightness temperature calculated from cloudy profile and the clear-sky brightness temperatures."

\section{d. Bias correction}

The same observation error bias model as used for the clearsky assimilation is also used for the all-sky assimilation system with a small adjustment: the bias correction coefficients are derived using selected quality controlled radiances where model and observed cloud information sufficiently agree and indicate nearly clear sky. Contrary to Zhu et al. (2016), where the criteria was the matching of cloud presence (or absence) in the background state and observation, we exclude observations with $\overline{\mathrm{CLW}}>0.05 \mathrm{~kg} \mathrm{~m}^{-2}$ from computing bias correction coefficients in the all-sky system. The clear and cloudy radiance data are then bias corrected using the latest available bias correction coefficients.

Cloud information from the model background state and observations is grouped into four categories: the observation and background state cloud free (O:clear/F:clear), the observation cloudy and the background state clear (O: cloudy/F:clear), the observation clear and the background state cloudy (O:clear/F:cloudy), and the observation and background state both cloudy (O:cloudy/F:cloudy). With our proposed approach, it is assumed that most of the observation bias in all four categories can be captured by the $\mathrm{O}$ :clear/F:clear category. The choice is justified because the 


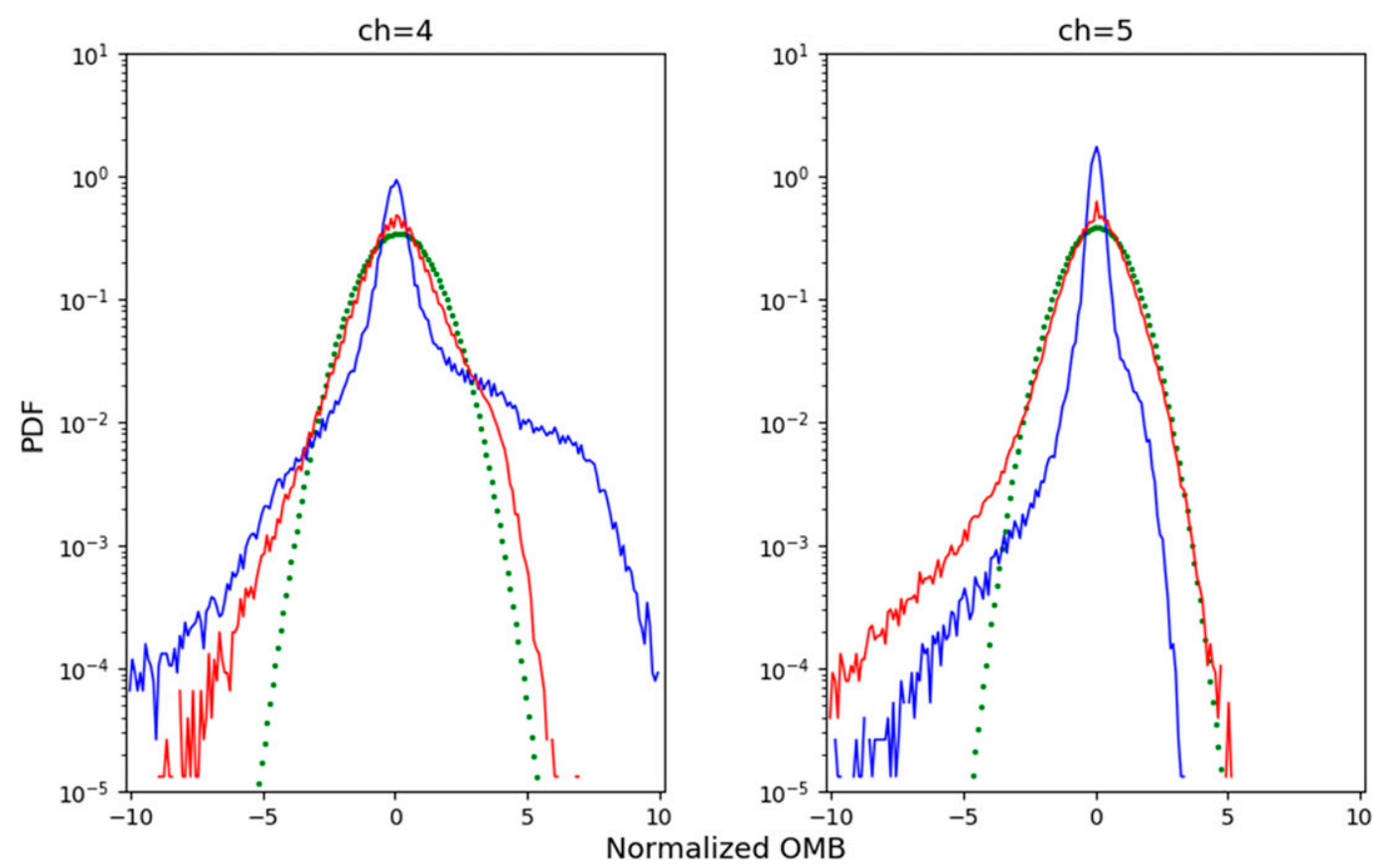

FIG. 2. The histograms of OMB for all AMSU-A channels (left) 4 and (right) 5 radiances over the ocean surface for the period from 1 to $5 \mathrm{Jul} 2019$, normalized by the sample stddev (blue) or by the fit to the all-sky innovation stddev (red). Gaussian distribution is shown in green dots.

areas where either the observation or background state is cloudy often correspond with large OMB values. The OMB become increasingly large with more cloud in clear and moderately cloudy scenes (below $\mathrm{CLW}_{\mathrm{avg}}=0.6 \mathrm{~kg} \mathrm{~m}^{-2}$ threshold), as shown by the state-dependent model for the innovation stddev, and the large OMB values can have large impact on the estimated bias correction values, even though the majority of the observations are clear-sky (Fig. 1). We do not take into account the cloud-dependent bias correction to ensure that the remaining model cloud bias does not impact the bias correction of the clear-sky observations.

\section{e. 4D-EnVar system}

In the initial set of all-sky assimilation experiments, the analysis increments are computed for the LCP variable in the 4D-EnVar assimilation system. Consequently, a new set of short-term ensemble forecasts was generated with LCP in the outputs to define the cross covariance between cloud and other state variables. The static NMC background covariance matrix does not include cloud, hence the cloud-related error covariances are solely defined with the ensembles. As LCP is a diagnostic variable in the atmospheric model, its increments are discarded and not used at the forecast step. Compared to the clear-sky assimilation framework, there are three major changes within the 4D-EnVar system for the allsky assimilation: 1) adding background error cross covariance between noncloud analyzed variables with LCP field; 2) using LCP for computing the innovations in the nonlinear observation operator and; 3) using LCP in the linearized observation operator.
In our original tests, the observation error stddev for the all-sky assimilation was set to the observation error inflation factor (IF) times the cloud-dependent innovation stddev $\sigma^{\text {all }}$ [Eq. (3)]. The all-sky assimilation experiments using this configuration did not produce satisfactory forecast scores. Large analysis increments were generated and large temperature and humidity biases were found in the extratropical regions where persistent cloud cover exists (plots not shown). In these experiments, we found assimilation of observations that have large disagreement with the background state in terms of cloud location and amount deteriorate the quality of temperature and humidity analysis. This is referred to as the "double-penalty" effect in Geer et al. (2012) and contributed to the forecast degradation in tropics in their original all-sky AMSU-A channels 4 and 5 assimilation tests.

As a workaround, similar to the Zhu et al. (2016), we introduced two new observation error inflation terms to lower the weight of observations during the analysis step when there is disagreement with the background-state cloud. The two inflation terms considered are based on the cloud placement and CLW differences between the observation and the background state. The difference in the cloud placement is based on $\left(\mathrm{CLW}_{\mathrm{obs}}-\right.$ $\left.\mathrm{C}_{\mathrm{clr}}\right) \times\left(\mathrm{CLW}_{\mathrm{FG}}-\mathrm{C}_{\mathrm{clr}}\right)<0$ and $\left|\mathrm{CLW}_{\mathrm{obs}}-\mathrm{CLW}_{\mathrm{FG}}\right| \geq 0.005$. If this condition is satisfied, the observation error inflation due to the difference in cloud placement between the observation and background state is $\sigma_{\text {inf1 }}^{O}=|\mathrm{OMB}|$, otherwise it is set to zero. The observation error inflation due to CLW difference is $\sigma_{\text {inf } 2}^{O}=\min \left(\gamma\left|\mathrm{CLW}_{\text {obs }}-\mathrm{CLW}_{\mathrm{FG}}\right| \sigma^{\text {all }}, 3.5 \sigma^{\text {all }}\right) \times \mathrm{IF}$, where $\gamma=$ $13.0 \mathrm{~m}^{2} \mathrm{~kg}^{-1}$, similar to Zhu et al. (2016), and IF is the clear-sky inflation factor. The final observation error stddev used at the 

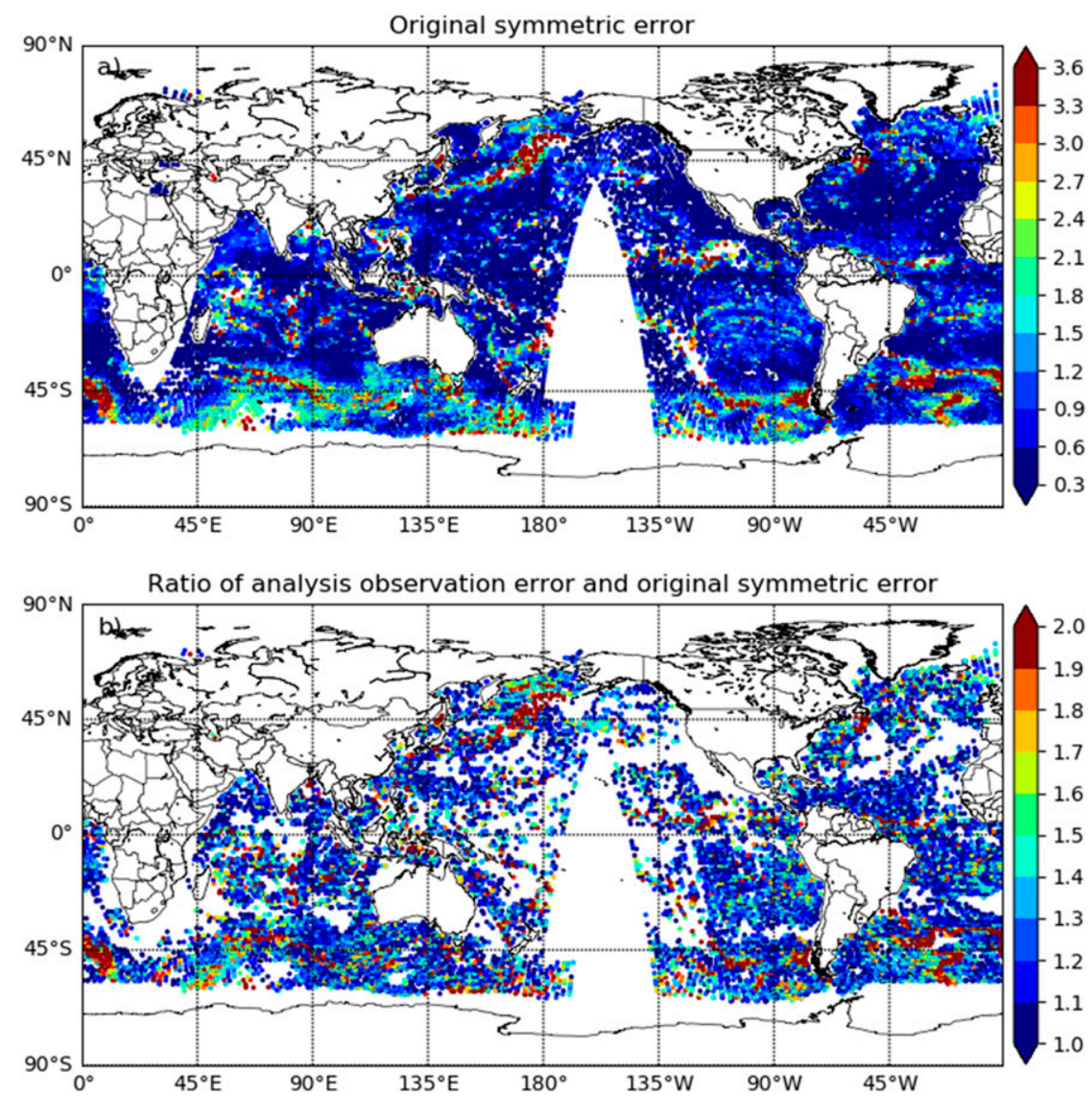

FIG. 3. (a) Original symmetric observation error stddev for assimilated AMSU-A channel 4 observations at the 0000 UTC 1 Jul 2019 analysis date. (b) The ratio of final and symmetric observation error stddev for when the ratio $>1$ for the same date.

analysis step is the combined original observation error and the two additional inflation terms:

$$
\sigma_{\text {analysis }}^{O}=\left[\left(\mathrm{IF} \sigma^{\mathrm{all}}\right)^{2}+\left(\sigma_{\text {inf } 1}^{O}+\sigma_{\text {inf2 }}^{O}\right)^{2}\right]^{0.5} .
$$

Figure 3 compares the original symmetric observation error stddev (IF $\sigma^{\text {all }}$, top panel) and the ratio of the final and original symmetric observation error stddev at the analysis step $\left[\sigma_{\text {analysis }}^{O} /\left(\mathrm{IF} \sigma^{\text {all }}\right)\right.$, bottom panel $]$ for assimilated AMSU-A channel 4 observations at 0000 UTC 1 July 2019 analysis date.

\section{Results}

\section{a. Experiments}

The ECCC global deterministic weather prediction system (Buehner et al. 2015; McTaggart-Cowan et al. 2019) was used to run 4D-EnVar assimilation experiments, using a forecast model with $15 \mathrm{~km}$ grid spacing for the background state and 39$\mathrm{km}$ grid spacing for the analysis increments, to examine the impact of all-sky assimilation of AMSU-A channels 4 and 5 over the ocean surface. Experiments were conducted for two periods of 2 months from 1 July to 31 August 2019 (summer
2019), and from 1 January to 28 February 2020 (winter 2020). For each period, the control experiment uses the clear-sky assimilation framework, similar to the current operational configuration at ECCC. In the modified experiment, the all-sky assimilation framework is activated. A brief list of modifications to change from the clear-sky to all-sky framework is mentioned in Table 3. The all-sky experiments were launched with the same initial conditions (including the dynamic bias correction coefficient for satellite radiances) as the clear-sky experiments.

\section{b. Impact on fit to the observations and data count}

It is difficult to do a clean comparison of the fit of the background state to the observations between the clear-sky and all-sky experiments, as pointed out in Geer et al. (2012) and Zhu et al. (2016). In addition to using model cloud in the observation operator, there are many other changes for transitioning from the clear-sky to all-sky framework (section 3) that contribute to the change to fit to observations.

The thinned bias-corrected AMSU-A and ATMS observations between $50^{\circ} \mathrm{S}$ and $50^{\circ} \mathrm{N}$ latitudes over the ocean surface (the latitudinal limits where AMSU-A channels 4 and 5 are assimilated in ECCC) were used to compute the 
TABLE 3. List of modifications to change from the clear-sky to all-sky framework.

\begin{tabular}{ll}
\hline \hline $\begin{array}{l}\text { Ensemble background covariance matrix } \\
\text { with cloud variable }\end{array}$ & Section 3e \\
Scaled model cloud used in observation & Section 3b \\
operator for simulation and & \\
assimilation of radiances & \\
New state-dependent model for the inno- & Section 3a \\
vation stddev for quality control and & \\
analysis & \\
Additional changes to quality control and & Sections 3c and 3e \\
analysis for the all-sky assimilation & Section 3d \\
$\begin{array}{l}\text { Using only clear background state and } \\
\text { observation for bias correction of the }\end{array}$ & \\
radiances. & \\
\hline
\end{tabular}

OMB for the clear-sky and all-sky experiments. Data were collected from the first month of each evaluation period (from 1-31 July 2019 to 1-31 January 2020) and OMB statistics were computed for each period separately. Quality control was not applied when sampling the data. The results for the two evaluation periods are very similar. The stddev of OMB in the all-sky experiment, normalized by the stddev of OMB in the clear-sky experiment for the 1-31 January 2020 evaluation period for AMSU-A and ATMS observations are shown in Fig. 4. The statistical significance is computed from an $F$ test with a $95 \%$ confidence level. For AMSU-A, there is a $2 \%$ increase in channel 4 stddev of OMB, whereas channel 5 stddev of OMB was reduced by $2 \%$ in the all-sky experiment. The observation error inflation at the analysis step seems to decrease the fit of the background state to the cloudaffected observations and therefore, the increase in AMSU-A channel 4 stddev of OMB was expected. The results for other AMSU-A channels were not statistically significant and the two experiments' performances are comparable. For ATMS, there is a $1 \%$ decrease and a $0.7 \%$ increase in stddev of OMB for channels 8 and 10 in the all-sky experiment. The $0.6 \%$ degradation of the fit to ATMS channel 10 is not statistically significant. There are no statistically significant differences between the two experiments for other ATMS temperature channels. There is a $1 \%$ increase in stddev of OMB for channel 16 and a $1.5 \%-3 \%$ reduction of stddev of OMB for upper tropospheric humidity channels 21 and 22 . Overall, the changes in fit of the background state to the AMSU-A and ATMS observations are mixed positive and negative.

The fit of the background state to GPSRO refractivity observations is also compared between the clear-sky and all-sky experiments during the first month of the two evaluation periods. The statistics are calculated with the global observations grouped in 2-km-thick layers between 0- and 60-km altitude above mean sea level. Similar to before, the comparisons are very similar between the two evaluation periods. Stddev of OMB in the all-sky experiment, normalized by the stddev of OMB in the clear-sky experiment, shows small statistically significant improvement $(\sim 0.5 \%)$ at 4 - and $13-\mathrm{km}$ altitudes during the summer period and 7 and $16 \mathrm{~km}$ during the winter period (not shown).
The fit of the background state to radiosonde observations is similar between the clear-sky and all-sky experiments (not shown). Overall, similar to Zhu et al. (2016) the results of our all-sky AMSU-A channels 4 and 5 assimilation experiments indicate mostly neutral impacts related to OMB statistics.

The number of AMSU-A channels 4 and 5 assimilated observations is increased by $5 \%-12 \%$ at each 6 -h assimilation window in the all-sky experiment. The increase in assimilated observation count is mostly in the Southern Hemisphere where there is more ocean coverage since these channels are only assimilated over the ocean surface. This number can be further augmented in future upgrades by relaxing the threshold $\overline{\mathrm{CLW}}<0.6 \mathrm{~kg} \mathrm{~m}^{-2}$ criteria used for quality control of the observations to a higher value.

\section{c. Impact on analysis}

The impacts of the all-sky approach on the analysis are expected for the regions where the background state or the observations are cloudy. The clear-sky and all-sky $850-\mathrm{hPa}$ temperature analyses of the summer experiments are compared against the ECMWF analyses for the first analysis of the summer period at 0000 UTC 1 July 2019 in Figs. 5a, 5b, respectively. For the same date and level, the temperature analysis increments are shown in Figs. 5c, 5d and the difference between the temperature analysis in the two experiments is shown in Fig. 5 e. Three regions $\left(1: 60^{\circ}-30^{\circ} \mathrm{S}, 80^{\circ}-120^{\circ} \mathrm{E} ; 2: 30^{\circ} \mathrm{S}-\right.$ $0^{\circ}, 85^{\circ}-105^{\circ} \mathrm{W}$; and $\left.3: 35^{\circ}-65^{\circ} \mathrm{N}, 160^{\circ} \mathrm{E}-180^{\circ}\right)$ are marked on the plots to highlight the differences between the clear-sky and all-sky experiments. Compared to the clear-sky, the all-sky experiment analysis is more consistent with the ECMWF temperature analysis (Figs. $5 \mathrm{~b}$ vs $5 \mathrm{a}$ ) by generating smaller temperature analysis increments (Figs. $5 \mathrm{~d}$ vs $5 \mathrm{c}$ ) which reduces the temperature analysis by $0.5-1 \mathrm{~K}$ (Fig. 5e) in regions 1 and 2. There are approximately 4000 extra AMSU-A channel 4 and 5 observations assimilated in the all-sky but not in the clear-sky experiment at this analysis date. These are the cloud-affected observations, with many located in regions $1-3$, that contribute to the differences seen between the clearsky and the all-sky experiments and are shown in Fig. 6 for the extra AMSU-A channel 4 observations. Using scaled cloud in the model for innovation stddev will induce small changes in the $850-\mathrm{hPa}$ temperature analysis on the order of $10^{-2} \mathrm{~K}$ (not shown). As will be discussed later, the cloud biases will be addressed in our future all-sky assimilation development with the goal of removing the need to use cloud scaling in DA system. Comparison of the clear-sky and all-sky $850-\mathrm{hPa}$ specific humidity analysis at 0000 UTC 1 July 2019 shows small differences, mostly in the tropical regions, between the two experiments (not shown). The relation between additional assimilated AMSU-A observations and more consistency with ECMWF analyzed temperature in the all-sky experiment exists at the other analysis times.

\section{d. Impact on upper-air forecasts}

The medium-range forecasts launched at 0000 and 1200 UTC were evaluated against radiosondes and ECMWF operational analyses. The verification against radiosondes did not show statistically significant differences between the clear-sky and all-sky 


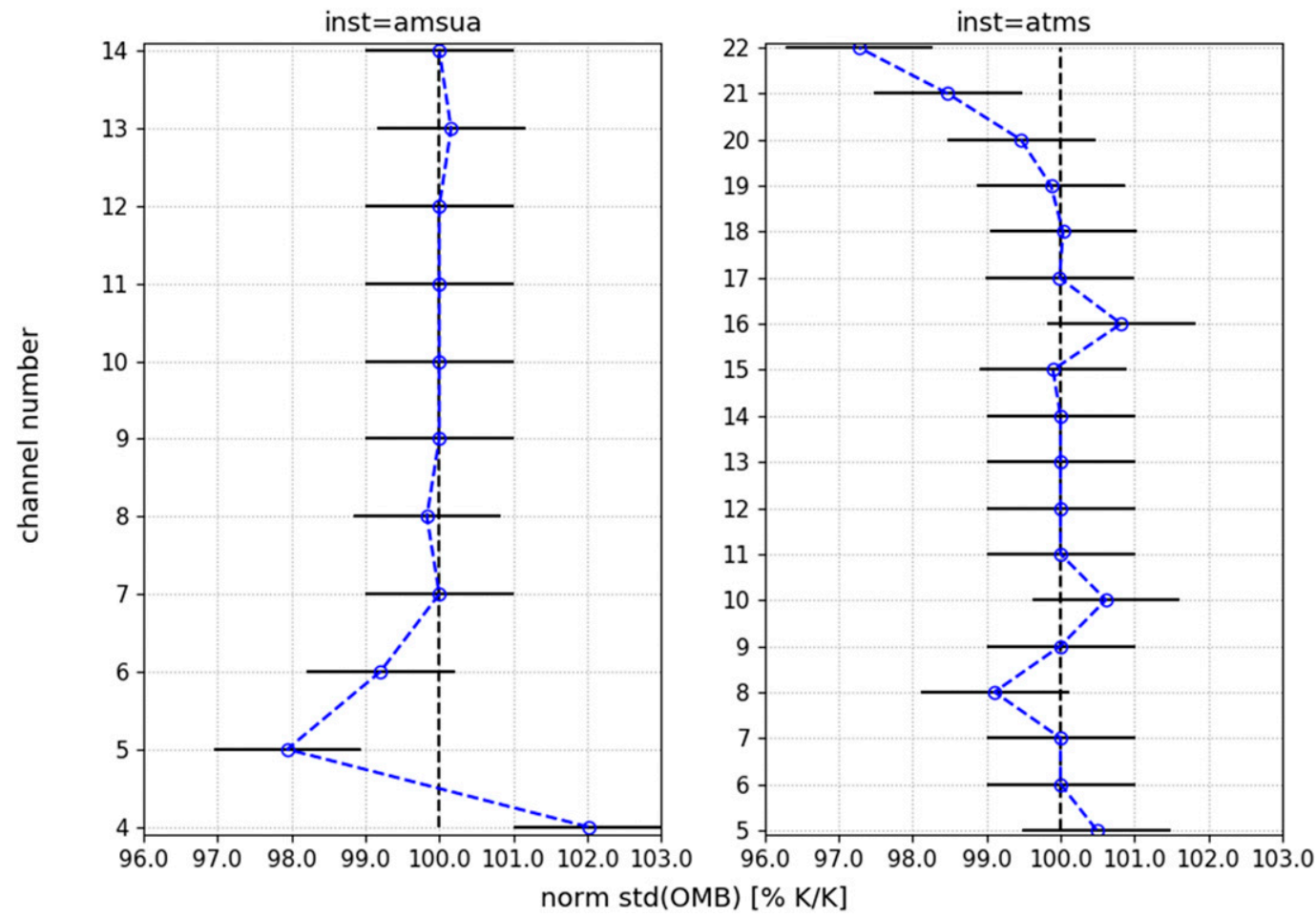

FIG. 4. Stddev of OMB of thinned bias-corrected (left) AMSU-A and (right) ATMS global observations for the all-sky experiment, normalized by the stddev of OMB of the clear-sky experiment. Error bars indicate significance interval from an $F$ test at the $95 \%$ confidence level. The statistics are calculated for the 1-31 Jan 2020 period.

experiments. This is expected as the geographical coverage of the radiosonde observations is limited to areas over land, away from regions where the cloudy observations are assimilated in the allsky system.

For the forecast verification against analyses, only the statistically significant differences between the two experiments are highlighted. The normalized difference in the stddev of the error of the temperature between the clear-sky and all-sky experiments $\left[\left(\sigma_{\text {clearSky }}-\sigma_{\text {allSky }}\right) / \sigma_{\text {clearSky }}\right]$ over the northern extratropics (NE), tropics (TR), and southern extratropics (SE) domains as a function of forecast lead time are shown for the summer 2019 and winter 2020 assimilation periods in Fig. 7. For the summer extratropics (NE for the summer 2019 and SE for the winter 2020 periods, Figs. 7a,f), there is a $2 \%-4 \%$ reduction in the stddev of the error of the temperature forecasts in the all-sky experiment in the lowerto-midtroposphere, up to a maximum of 4 days. Over the tropics in the all-sky experiment, the stddev of the error in the temperature forecasts is reduced by $2 \%-3 \%$ in the midtroposphere from day 2 to 4 for the summer 2019 (Fig. 7b), and at $850 \mathrm{hPa}$ up to 2 days for the winter 2020 period (Fig. 7e). Forecast scores from the clear-sky and all-sky experiments are comparable in the winter extratropics (SE for the summer 2019 and NE for the winter 2020 periods, Figs. 7c,d). This might be due to the assimilation of more nonprecipitating cloudy observations in the summer extratropics, where persistent clouds exist over the ocean surface, whereas the winter extratropics are usually associated with more severe weather and the cloudy observations are most probably precipitating and rejected.

The normalized difference in the stddev of the error of the specific humidity and horizontal wind speed between the two experiments over the NE, TR, and SE domains as a function of forecast lead time are also displayed for the two seasons in Figs. 8 and 9, respectively. In the summer extratropics with the all-sky experiment, there is a reduction of the stddev of the error of the specific humidity at levels $1000 \mathrm{hPa}$ by $2 \%-4 \%$ for $1-2$ days, and at $850 \mathrm{hPa}$ by $1 \%-2 \%$ that extends beyond day 2 during the winter 2020 period (Figs. 8a,f). The two experiments produce comparable results in the winter extratropics (Figs. 8c,d) while the tropical stddev of the error of the specific humidity is improved by $1 \%-4 \%$ at $1000 \mathrm{hPa}$ and in the mid- to uppertroposphere by $2 \%-3 \%$ up to day 2 (Figs. 8 b,e). The two experiments perform similarly for the horizontal wind forecast during the summer 2019 period (Figs. 9a-c) while there is a $1 \%-2 \%$ reduction in the stddev of the error of low- and midtropospheric horizontal wind speed in the all-sky experiment up to 1 day in the TR and SE domains during the winter 2020 period (Figs. 9e,f). Overall, the positive impact of the all-sky assimilation of AMSU-A channels 4 and 5 is up to a maximum $4 \%$ reduction in the stddev of the error for the temperature, specific humidity, and horizontal wind speed in the lower- and midtroposphere with the largest improvements up to 2 days in forecasts in several regions/seasons.

The all-sky assimilation of AMSU-A channels 4 and 5 resulted in degradation of $850 \mathrm{hPa}$ temperature forecasts in the 

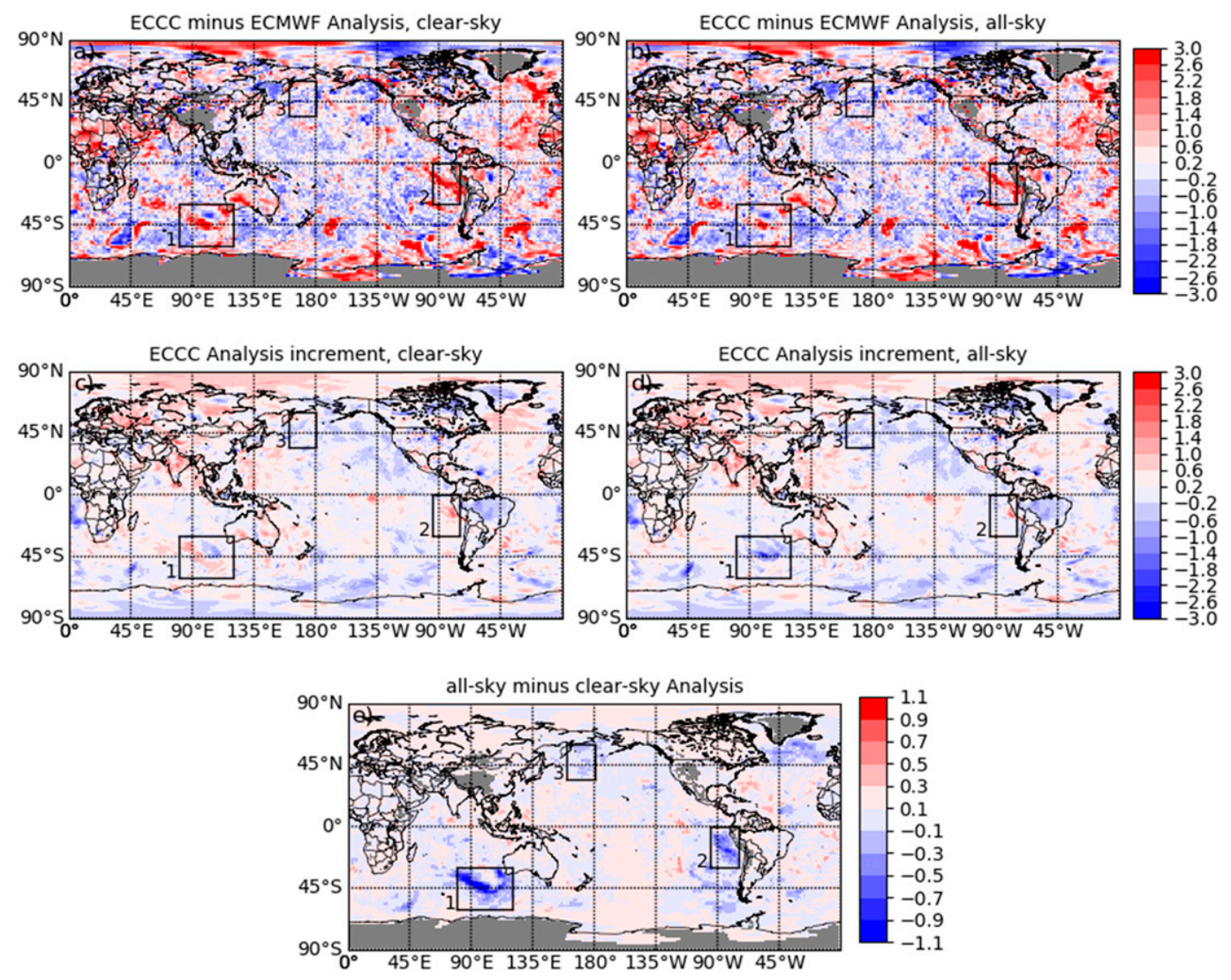

FIG. 5. Difference in 850-hPa temperature analysis (K) at 0000 UTC 1 Jul 2019 between ECMWF and the (a) clear-sky and (b) all-sky experiments. Temperature analysis increments (K) at $850 \mathrm{hPa}$ for the (c) clear-sky and (d) all-sky experiments for the same date. (e) Difference in 850-hPa temperature analysis (K) between the clear-sky and all-sky experiments. Plots in each row have common color scales. Three regions $\left(1: 60^{\circ}-30^{\circ} \mathrm{S}, 80^{\circ}-120^{\circ} \mathrm{E} ; 2\right.$ : $30^{\circ} \mathrm{S}-0^{\circ}, 85^{\circ}-105^{\circ} \mathrm{W}$, and $3: 35^{\circ}-65^{\circ} \mathrm{N}, 160^{\circ} \mathrm{E}-180^{\circ}$ ) are marked on the plots to highlight the differences between the clear-sky and all-sky experiments.

tropics at ECMWF (Geer et al. 2012), contrary to the results obtained here. The different results between ECMWF and ECCC could have multiple origins: 1) different assimilation systems, i.e., 4D-EnVar at ECCC and 4DVar at ECMWF; 2) different model cloud biases in the two systems and the cloud scaling method used at ECCC to mitigate the model cloud overestimation; 3 ) the all-sky assimilation of microwave imaging channels already constrained the low-tropospheric analysis at ECMWF and the subsequent all-sky assimilation of AMSU-A temperature channels did not add new observational information; 4) at ECCC, the "double-penalty" effect (Geer et al. 2012) was reduced by the additional observation error inflation during the analysis step, similar to the Zhu et al. (2016).

\section{e. Impact of not computing analysis increments for cloud}

We want to evaluate how much of the all-sky assimilation positive forecast impacts seen in the previous section are due to using the background error cross-covariance between noncloud analyzed variables with the LCP field and computing the LCP analysis increment. For this test, the analysis increments for LCP are not computed and there is no cross-covariance between LCP and other noncloud analyzed variables in the all-sky experiment. Compared to the clear-sky assimilation framework, in this configuration the background-state LCP is still used for 1) computing the innovations in the nonlinear observation operator and 2) linearizing the observation operator.

A modified all-sky experiment was conducted for the period of 1 January-1 February 2020 with the same setup as the original all-sky experiment for the winter 2020 period. The forecasts' verification against radiosondes and ECMWF operational analyses showed the two flavors of all-sky experiments perform very similarly and the differences were not statistically significant. This implies that the all-sky assimilation forecast improvements result mainly from the use of cloud information for computing the innovations. To save time in the analysis step, it was decided to remove LCP as an analyzed variable in the global deterministic prediction system for the operational implementation planned for the fall of 2021.

\section{Summary and future work}

At Environment and Climate Change Canada (ECCC), only the clear-sky radiances are assimilated within the operational 


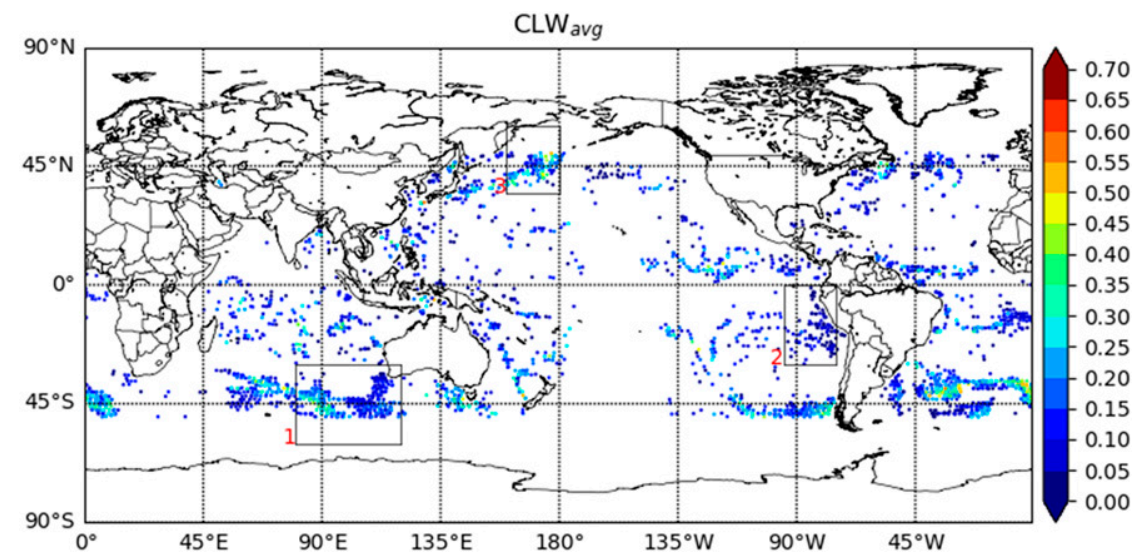

FIG. 6. Averaged cloud liquid water $\left(\mathrm{CLW}_{\mathrm{avg}} \mathrm{kg} \mathrm{m}^{-2}\right)$ at locations where AMSU-A channel 4 observations are assimilated in the all-sky but not the clear-sky experiment at 0000 UTC 1 Jul 2019. The three highlighted regions correspond to the same regions marked in Fig. 5.

4D-EnVar system. This study demonstrates the initial steps toward the all-sky assimilation of microwave radiances in the Canadian global deterministic weather prediction system. To do so, necessary changes are made within the global data assimilation system, including modifications to the specified radiance observation error statistics, quality control, bias correction, and the 4D-EnVar analysis system. We focus on the assimilation of cloud-affected AMSU-A channels 4 and 5 observations for non-precipitating scenes over the ocean surface. This study only partially addresses the "all-sky" approach

Normalized difference in stddev of error for temperature
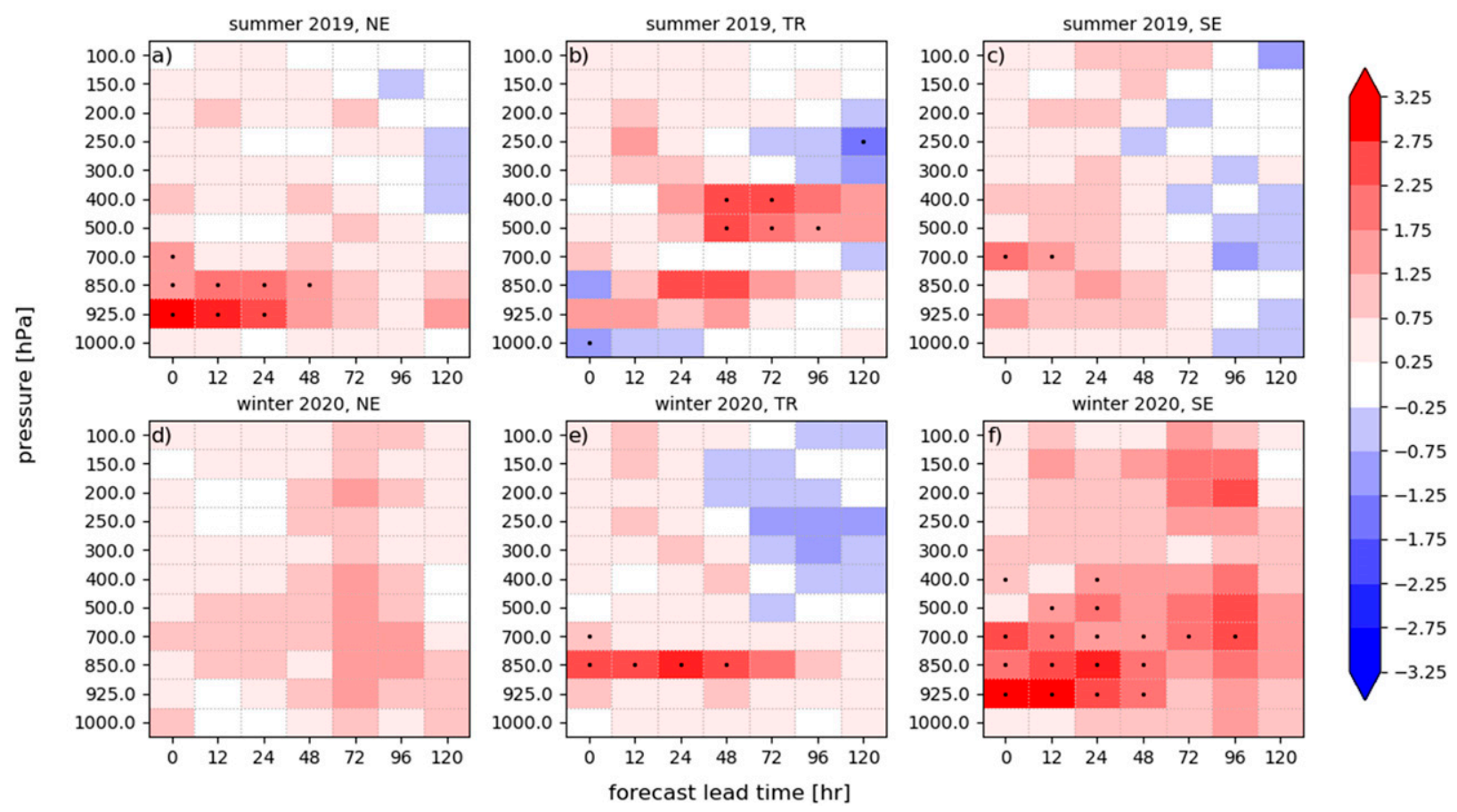

FIG. 7. The difference in the stddev of the error of the temperature between the clear-sky and all-sky experiments normalized by the stddev of the error of the temperature of the clear-sky experiment in percent $\left[100 \times\left(\sigma_{\text {clearSky }}-\sigma_{\text {allSky }}\right) / \sigma_{\text {clearSky }}\right]$ over $(\mathrm{a}),(\mathrm{d})$ northern extratropics (NE); (b),(e) tropics (TR); and (c),(f) southern extratropics (SE) domains as a function of forecast lead time for the (a)-(c) summer 2019 and (d)-(f) winter 2020 assimilation periods, with ECMWF analyses used as reference. Red contours show better all-sky and blue contours show better clear-sky, when verified against the reference analyses. The black dots on the plot show the statistically significant results above the $90 \%$ confidence level from the $F$ test. 

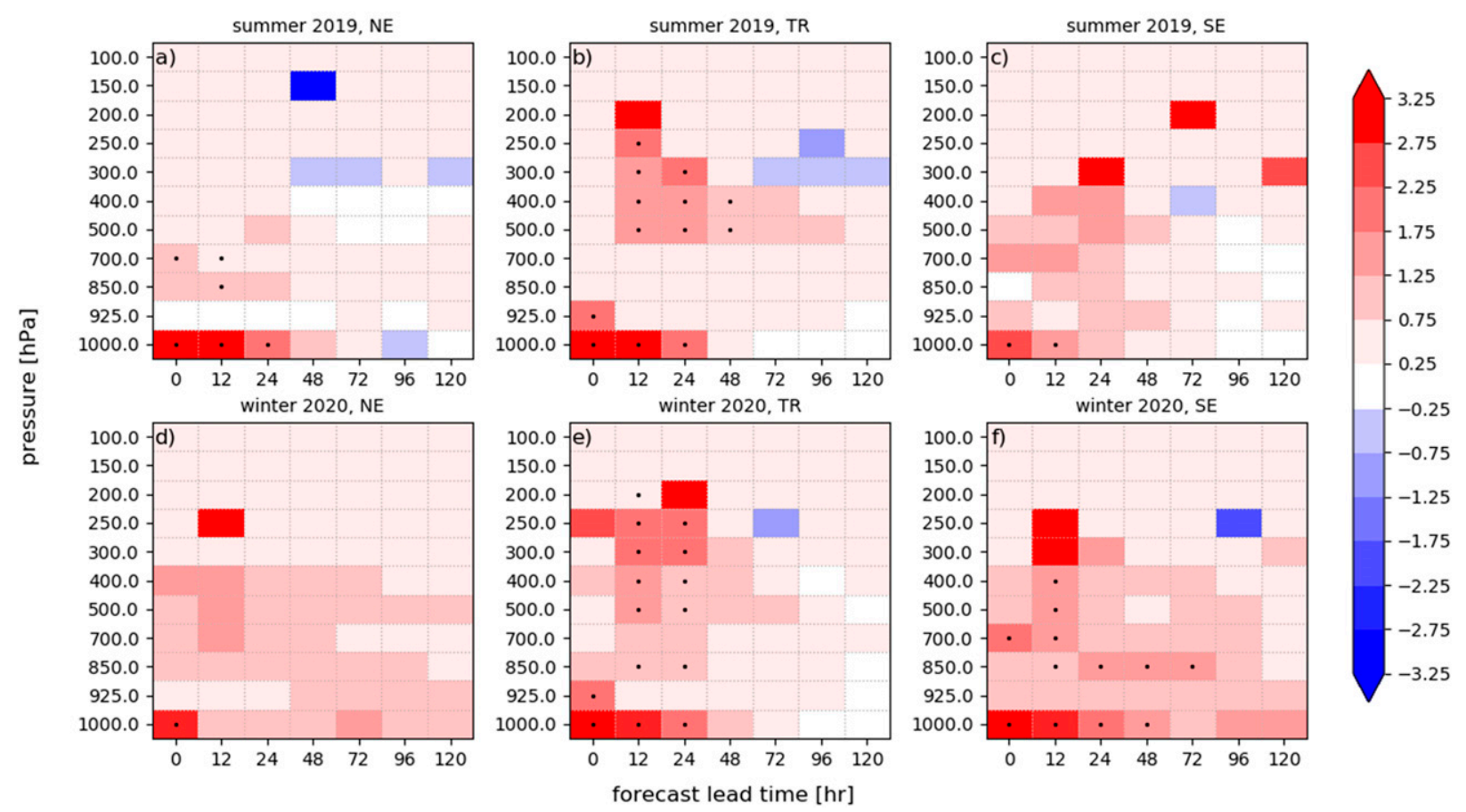

FIG. 8. As in Fig. 7, but for specific humidity.

applied to AMSU-A, since the data in precipitating areas are still not used.

The symmetric model for the innovation stddev, proposed by Geer and Bauer (2011) and Geer et al. (2012), the piecewise linear fit to standard deviation (stddev) of innovation (OMB) binned by the averaged cloud liquid water (CLW) retrievals from the observation $\left(\mathrm{CLW}_{\mathrm{obs}}\right)$ and background state $\left(\mathrm{CLW}_{\mathrm{FG}}\right)$, is used to define the AMSU-A observation error stddev. A new quality control test based on cloud effect of channel 5 AMSU-A (Geer et al. 2012) is created to screen out observations affected by extreme scattering in deep convective regions. For bias correction, only when the observation and background state are both cloud-free, the observation is used in the calculation of the bias correction coefficients. Two additional observation error inflation terms, based on the cloud placement and CLW differences between the observation and the background state (Zhu et al. 2016), are introduced at the analysis step to adjust the weight of cloudy observations when the observation cloudiness does not agree with the background-state cloud. The symmetric model for the innovation stddev was shown to be able to describe the OMB statistics and bring the OMB distribution closer to Gaussian.

The analysis increments are computed for the Liquid Cloud Profile (LCP) variable, and used in combination with the modelderived LCP background state for the simulation and assimilation of AMSU-A observations over the ocean surface. As the background-state clouds are largely overestimated at ECCC, they are scaled globally by a 0.5 multiplicative factor, which is applied to the vertical cloud profile, before using the profile in the observation operator. For the background error covariance matrix, the cross-covariance between cloud and other variables is only defined by the 256-member ensembles, as the static NMC background covariance matrix does not include the cloud variable.

Global 4D-EnVar assimilation experiments were conducted for two periods of two months from 1 July to 31 August 2019 (summer 2019), and from 1 January to 28 February 2020 (winter 2020) to evaluate the impact of the all-sky assimilation of AMSUA channels 4 and 5 over the ocean surface. For each period, the control experiment uses the clear-sky assimilation framework, similar to the current operational configuration at ECCC.

The fit of the background state to the AMSU-A observations showed a $2 \%$ increase and $2 \%$ decrease in channels 4 and 5 stddev of OMB in the all-sky experiment. For ATMS, there is a $1 \%$ decrease for channel $8,1 \%$ increase for channel 16 , and $1.5 \%-3 \%$ decrease for upper-tropospheric humidity channels 21 and 22 of the stddev of OMB during both periods in the all-sky experiment. Fit to GPSRO observations showed small statistically significant improvement $(\sim 0.5 \%)$ at 4 - and 13 -km altitudes during the summer period and 7 and $16 \mathrm{~km}$ during the winter period in the all-sky experiment. The number of AMSU-A channels 4 and 5 assimilated observations is increased by $5 \%-$ $12 \%$, mostly in the Southern Hemisphere where there is more ocean coverage, in the all-sky experiment.

The clear-sky and all-sky 850-hPa temperature analyses of the summer experiments are compared against the ECMWF analyses for 0000 UTC 1 July 2019. The all-sky experiment is shown to have a closer temperature analysis to ECMWF by generating smaller temperature analysis increments. The short- and medium-range forecasts were evaluated against 
Normalized difference in stddev of error for horizontal wind
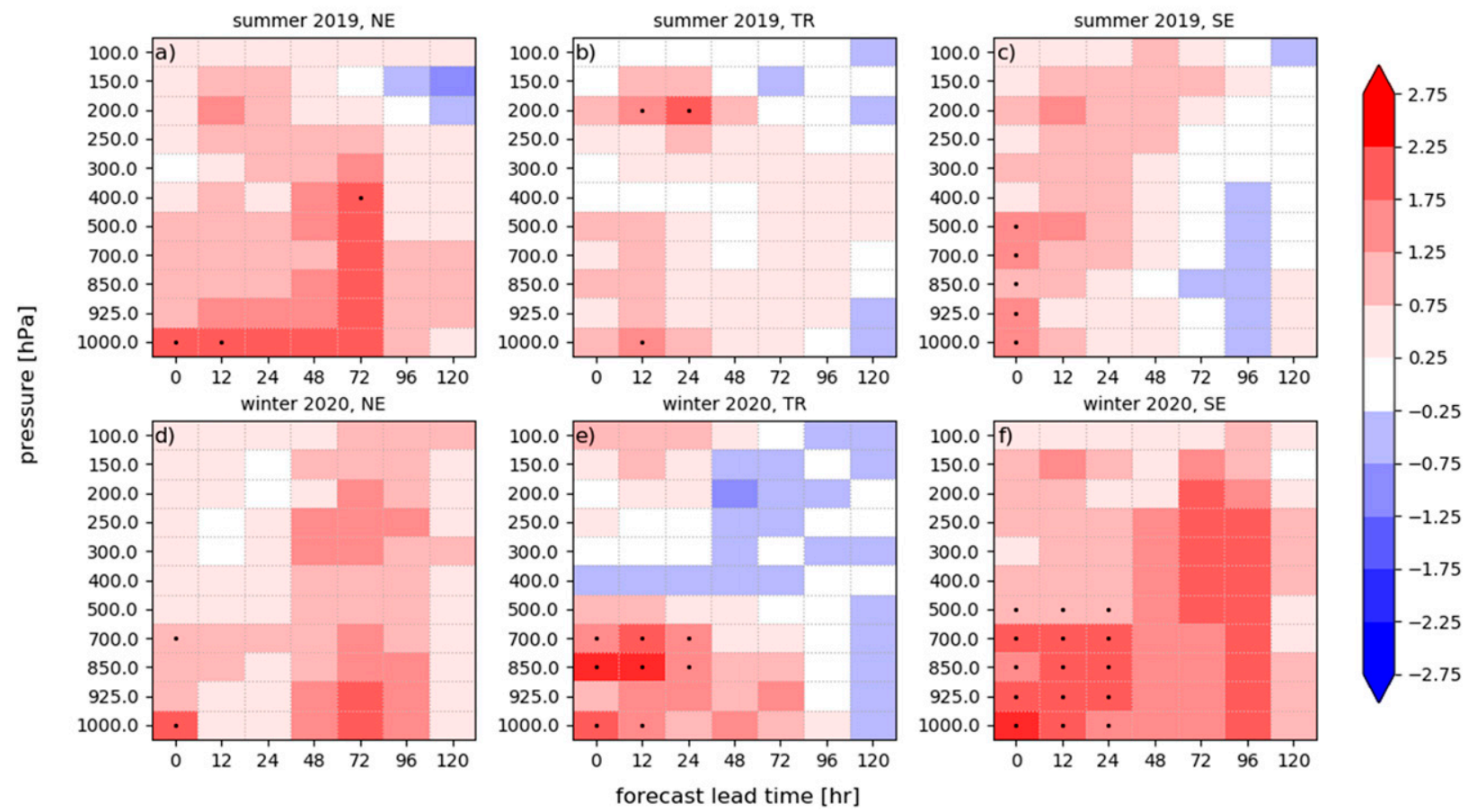

FIG. 9. As in Fig. 7, but for horizontal wind speed.

radiosondes and ECMWF operational analyses for the two test periods over the northern extratropics (NE), tropics (TR), and southern extratropics (SE) domains. The verification against radiosondes did not show statistically significant differences between the clear-sky and all-sky experiments. In the summer extratropics, there is a $2 \%-4 \%$ reduction in the stddev of the error of the temperature forecast in the all-sky experiment in the lower troposphere, up to a maximum of 4 days, when verifying against ECMWF operational analyses. Over the tropics, the stddev of the error of temperature forecasts is improved by $2 \%-3 \%$ from day $2-4$ in the midtroposphere for the summer 2019 and up to 2 days at $850 \mathrm{hPa}$ for the winter 2020 period in the all-sky experiment. For specific humidity, in the summer extratropics with the all-sky experiment, there is a reduction of the stddev of the error at $1000 \mathrm{hPa}$ by $2 \%-4 \%$ for $1-2$ days, and $850 \mathrm{hPa}$ by $1 \%-2 \%$ that extends beyond day 2 during the winter 2020 period. The tropical stddev of the error of the specific humidity is improved by $1 \%-4 \%$ at $1000 \mathrm{hPa}$ and in the mid- to uppertroposphere by $2 \%-3 \%$ up to day 2 in the all-sky experiment. There is a $1 \%-2 \%$ reduction in the stddev of the error of lowand midtropospheric horizontal wind speed in the all-sky experiment up to 1 day in the tropical and southern extratropics domains during the winter 2020 period. Overall, the positive impact of the all-sky assimilation of AMSU-A channels 4 and 5 is up to a maximum $4 \%$ reduction in the stddev of the error for the temperature, specific humidity, and horizontal wind speed in the lower- and midtroposphere with the largest improvements up to 2 days in forecasts in several regions/seasons. This is in contrast to the results from the allsky assimilation of AMSU-A channels 4 and 5 at NCEP shown in Zhu et al. (2016), which reported small improvements in RMSE of temperature forecasts in the tropics and Southern Hemisphere at $850 \mathrm{hPa}$, and neutral impact on temperature and wind forecasts in other regions and lead times. The different results for the all-sky assimilation of AMSU-A channels 4 and 5 between ECMWF and ECCC could have multiple origins: 1) different assimilation systems; 2) different model cloud biases; 3 ) constrained low-tropospheric analysis at ECMWF from the prior all-sky assimilation of microwave imaging channels; and 4) reduction of the "double-penalty" effect (Geer et al. 2012) by the additional observation error inflation in the analysis at ECCC.

An additional all-sky experiment was conducted for the period of 1 January-1 February 2020 where the analysis increments are not computed for the cloud variable. The forecasts' verification against radiosondes and ECMWF operational analyses showed the two flavors of all-sky experiments perform very similarly and the differences were not statistically significant, implying that the all-sky assimilation forecast impacts result mainly from the use of cloud information for computing the innovations. To save computational time in the analysis step, it was decided to remove LCP as an analysis variable in the global deterministic prediction system for the operational implementation in the fall of 2021.

This work is the first attempt toward the all-sky radiance assimilation at ECCC and there is room for improvement. Similar to Zhu et al. (2016), refinement of the symmetric model for the 
innovation stddev might be necessary, such as including a dependency on scan position or latitudinal band as reported in Geer et al. (2012). Tests with different model cloud variables should be performed to identify the best choice for model cloud representation for the all-sky assimilation of radiances. To improve the cloud field used within the data assimilation system and the removal of the need for application of an ad hoc cloud scale factor multiple options will be considered: 1) assimilating only the cloudy observations with a 1DVar or 3DVar to produce a corrected background-state cloud field that is then used during the 4D-EnVar analysis; 2) adding outer-loop to the minimization to further linearize the observation operator where the highly nonlinear cloudy observations are considered for assimilation from now on; and 3) reducing cloud biases in the data assimilation system by modifying the model cloud parameterization and/or applying the cloud analysis increments to the prognostic cloud field. It is planned to extend the all-sky capability to temperature channels of other microwave instruments, such as ATMS, in the near future. Additionally, an upgrade in the observation operator from RTTOV to RTTOV-SCATT is expected in the near future to facilitate the extension of the allsky functionality to the humidity channels of microwave instruments, where the impact of scattering by hydrometeors becomes nonnegligible. The all-sky assimilation of AMSU-A channels 4 and 5 over the ocean surface is planned for operational implementation at ECCC in the fall of 2021.

Acknowledgments. The authors wish to thank Stéphane Laroche for helping to analyze the results and review of the paper. Ervig Lapalme and Sylvain Heilliette are thanked for their technical support to run the tests and operational implementation. Paul Vaillancourt is thanked for helpful discussions on details of model physics parametrizations. We also want to thank Alan Geer (ECMWF), Stefano Migliorini (Met Office), Yanqiu Zhu (NASA), and Mingjing Tong (NOAA) for their comments and suggestions.

\section{REFERENCES}

Bauer, P., A. J. Geer, P. Lopez, and D. Salmond, 2010: Direct 4D-Var assimilation of all-sky radiances. Part I: Implementation. Quart. J. Roy. Meteor. Soc., 136, 1868-1885, https://doi.org/10.1002/qj.659.

Buehner, M., and Coauthors, 2015: Implementation of deterministic weather forecasting systems based on ensemble-variational data assimilation at Environment Canada. Part I: The global system. Mon. Wea. Rev., 143, 2532-2559, https://doi.org/10.1175/MWRD-14-00354.1.

__, P. Du, and J. Bédard, 2018: A new approach for estimating the observation impact in ensemble-variational data assimilation. Mon. Wea. Rev., 146, 447-465, https://doi.org/10.1175/ MWR-D-17-0252.1.

Geer, A. J., and P. Bauer, 2011: Observation errors in all-sky data assimilation. Quart. J. Roy. Meteor. Soc., 137, 2024-2037, https://doi.org/10.1002/qj.830.

$\longrightarrow,-$, and S. J. English, 2012: Assimilating AMSU-A temperature sounding channels in the presence of cloud and precipitation. ECWMF Tech. Memo. 670, https://doi.org/10.21957/mbjps5x4j.

_ , and Coauthors, 2017: The growing impact of satellite observations sensitive to humidity, cloud and precipitation. Quart. J. Roy. Meteor. Soc., 143, 3189-3206, https://doi.org/10.1002/qj.3172.
—_, and Coauthors, 2018: All-sky satellite data assimilation at operational weather forecasting centres. Quart. J. Roy. Meteor. Soc., 144, 1191-1217, https://doi.org/10.1002/qj.3202.

Grody, N., F. Weng, and R. Ferraro, 1999: Application of AMSU for obtaining water vapor, cloud liquid water, precipitation, snow cover and sea ice concentration. Preprints, 10th Int. TOVS Study Conf., Boulder, CO, Int. ATOVS Working Group, 230-240.

— J. Jhao, R. Ferraro, F. Weng, and R. Boers, 2001: Determination of precipitable water and cloud liquid water over oceans from the NOAA-15 Advanced Microwave Sounding Unit. J. Geophys. Res., 106, 2943-2953, https://doi.org/10.1029/2000JD900616.

Houtekamer, P. L., M. Buehner, and M. De La Chevrotière, 2019: Using the hybrid gain algorithm to sample data assimilation uncertainty. Quart. J. Roy. Meteor. Soc., 145, 35-56, https:// doi.org/10.1002/qj.3426.

Kazumori, M., and T. Kadowaki, 2017: Development of an all-sky assimilation of microwave imager and sounder radiances for the Japan Meteorological Agency global numerical weather prediction system. 21st Int. TOVS Study Conf., Darmstadt, Germany, International ATOVS Working Group, 9 pp., https:// cimss.ssec.wisc.edu/itwg/itsc/itsc21/proceedings/5.04_kazumori.pdf.

McTaggart-Cowan, R., and Coauthors, 2019: Modernization of atmospheric physics parameterization in Canadian NWP. J. Adv. Model. Earth Syst., 11, 3593-3635, https://doi.org/ 10.1029/2019MS001781.

Migliorini, S., and B. Candy, 2019: All-sky satellite data assimilation of microwave temperature sounding channels at the Met Office. Quart. J. Roy. Meteor. Soc., 145, 867-883, https:// doi.org/10.1002/qj.3470.

Parrish, D. F., and J. C. Derber, 1992: The National Meteorological Center's spectral statistical interpolation analysis system. Mon. Wea. Rev., 120, 1747-1763, https://doi.org/10.1175/15200493(1992) $120<1747:$ TNMCSS $>2.0$.CO;2.

Saunders, R., and Coauthors, 2018: An update on the RTTOV fast radiative transfer model (currently at version 12). Geosci. Model Dev., 11, 2717-2737, https://doi.org/10.5194/gmd-11-2717-2018.

Shahabadi, M. B., J. Aparicio, and L. Garand, 2018: Impact of slant-path radiative transfer in the simulation and assimilation of satellite radiances in Environment Canada's Weather Forecast System. Mon. Wea. Rev., 146, 4357-4372, https:// doi.org/10.1175/MWR-D-18-0126.1.

_ _ S. Bélair, B. Bilodeau, M. L. Carrera, and L. Garand, 2019: Impact of weak coupling between land and atmosphere data assimilation systems on Environment and Climate Change Canada's Global Deterministic Prediction System. Wea. Forecasting, 34, 1741-1758, https://doi.org/10.1175/WAF-D19-0073.1.

—, M. Buehner, J. Aparicio, and L. Garand, 2020: Implementation of slant-path radiative transfer in Environment Canada's Global Deterministic Weather Prediction System. Mon. Wea. Rev., 148, 4231-4245, https://doi.org/10.1175/MWR-D-20-0060.1.

Tong, M., Y. Zhu, L. Zhou, E. Liu, M. Chen, Q. Liu, and S.-J. Lin, 2020: Multiple hydrometeors all-sky microwave radiance assimilation in FV3GFS. Mon. Wea. Rev., 148, 2971-2995, https://doi.org/10.1175/MWR-D-19-0231.1.

Zhu, Y., and Coauthors, 2016: All-sky microwave radiance assimilation in NCEP's GSI analysis system. Mon. Wea. Rev., 144, 4709-4735, https://doi.org/10.1175/MWR-D-15-0445.1.

—, G. Gayno, R. J. Purser, X. Su, and R. Yang, 2019: Expansion of the all-sky radiance assimilation to ATMS at NCEP. Mon. Wea. Rev., 147, 2603-2620, https://doi.org/10.1175/MWR-D18-0228.1. 